\title{
Teachers' Perceptions on the Use of ICT in a CAL Environment to Enhance the Conception of Science Concepts
}

\author{
Frikkie George*, M Ogunniyi \\ Department of Education, University of the Western Cape, South Africa
}

Copyright $(\mathcal{C} 2016$ by authors, all rights reserved. Authors agree that this article remains permanently open access under the terms of the Creative Commons Attribution License 4.0 International License

\begin{abstract}
Instructional methodologies increasingly require teachers' efficacy and implementation of computer-assisted learning (CAL) practices in general and particularly in the science classroom. The South African National Education Department's e-Education[1] policy also encourages the use of computers and computer software in implementing outcome-based curriculum in the teaching and learning processes, proclaiming that; "South African learners in the General Education and Training (GET) and Further Education and Training (FET) bands are expected to be information communication technology (ICT) literate by 2013". Therefore, teachers also have to become ICT-literate and conversant with the ICT-resources that is available at schools. ICT can help learners conceptualise invisible and abstract science processes, models and concepts. The intention to use technology can be influenced by various variables such as perceived ease of use, perceived usefulness, attitude towards technology and motivation[2]. The aim of this study was twofold: To assess the availability of ICT resources and use in the selected science classrooms; and to determine the interviewed science teachers' perceived intention to use ICT in their classrooms. The theoretical framework of this study is based on the Technology Acceptance Model (TAM) of Davis[2], which is rooted to the Theory of Reasoned Action[3]. The sample for the ICT-survey was ten randomly selected high schools and 45 science teachers, who completed a TAM-questionnaire. This study found that most of the selected schools did have at least the basic ICT-resources in the science classrooms, but it was not used optimally. It was also concluded that the perceived usefulness of ICT-resources seemed to be the most influential factor for the teachers' intention to practise CAL. The results of this study could be useful for education authorities and school managements to solve the problem of under-utilisation of technologies at schools.
\end{abstract}

Keywords Information Communication Technology, Technophobia, Computer-assisted Learning, Perceptions, Ease of Use, Usefulness and Intention to Use

\section{Introduction}

Since the 70's, various researchers have been interested in factors that explain or predict the use of different technologies[4]. In 1983, Time magazine named the microcomputer their "Man of the Year", which resulted in a drive by institutions and public schools in particular to make use of computers[5]. Globally, research findings over the past 20 years provide some evidence about the positive effects of the use of information communications technology (ICT) on learners' learning $[6,7,8]$. However, in spite of such findings and numerous training programmes and investment by schools in ICT resources, there has been a disappointingly slow uptake of ICT in schools[9]. ICT and in particular computer-assisted learning (CAL) forms an increasingly important part of lesson activities in the classroom recently. Teachers also have to become ICT-literate and conversant with the ICT-resources that is available to them.

Research showed that teachers' beliefs influenced technology use in their classrooms and teachers with positive views about the use of technology in general, use computers in their lessons[10]. In many cases, the teachers with technophobic tendencies refrain from making use of computers and mainly make use of the traditional teaching methods, although they do have access to ICT-resources. The general assumption, and the e-Education policy of the education department, is that the use of ICT-resources will provide a platform for $\mathrm{CAL}$ which will provide teachers and learners with a wide range of interesting opportunities for creating different levels of interactivity. For that reason, many classrooms in South African schools are equipped with computers or some sort of ICT-resources.

Pertaining to the teaching of science, ICT can help learners to understand abstract ideas, invisible processes, complex models and concepts like, energy, molecules, electrons, electric current, chromosomes. Geer and Sweeney[6] assert that, "Technology should be used to enhance learning; therefore, it is important for teachers to comfortable use it to ensure that the learners get the full advantages of available educational technology". In order for this to happen, the teachers must be willing to use the 
ICT-resources available to them. The effective utilisation of ICT-resources will lead to the successful implementation of CAL, but it largely depends on the willingness of teachers to make use of these resources.

\section{Research Questions}

In this paper the following research questions were pursued:

1. Are the selected schools well equipped with the relevant ICT-resources for CAL?

2. Do the science teachers at the selected schools use the ICT-resources optimally?

3. Which factors (perceived ease of use, perceived usefulness and external control) influence the teachers' intention to make use of ICT in the classroom?

\section{Theoretical Framework}

The theoretical framework of this study is based on the Technology Acceptance Model[2], which is linked to the Theory of Reasoned Action[3]. The Technology Acceptance Model (TAM) represents one of the explanatory models having most influenced the theories of human behaviour[11]. TAM was developed with the primary aim of identifying the determinants involved in computer acceptance in general and to examine a variety of information technology usage behaviours. Davis, Bagozzi and Warshaw[12] assert that TAM explains why a user accepts or rejects information technology. TAM provides a basis with which one traces how external variables influence beliefs, attitudes and intention to use technology.
Two cognitive beliefs are posited by the TAM; perceived usefulness (degree to which the technology will improve achievement) and perceived ease of use (degree of easiness to use the technology). According to the TAM, the actual use of a technology is influenced directly or indirectly by the user's behavioural intentions, attitude, perceived usefulness and perceived ease of the technology. In addition, the TAM proposes that external factors (self-efficacy, anxiety, motivation, external control, etc.) affect intention and actual use through mediated effects on perceived usefulness and perceived ease of use. Figure 1 depicts the original technology acceptance theory[2].

\section{Methodology}

This research was a case study with both a qualitative and a qualitative approach. An ICT-survey was used to determine the availability and use of ICT-resources at the selected schools and its relevance to CAL. This survey consists of three parts; demographic information (Section A), available ICT-resources (Section B) and usage of the ICT-resources (Section C). The science teachers from the selected schools completed a TAM-questionnaire to determine their behavioural intention to make use of ICT during their lessons. Afterwards they were interviewed to determine their perceptions of CAL. The TAM-questionnaire consists of the three categories used to determine their behavioural intention to make use of ICT, namely; perceived usefulness, perceived ease of use and perceived external control towards ICT. The responses of the questionnaires and interviews were used to determine which factors are most influential to the teachers' intention to make use of ICT.

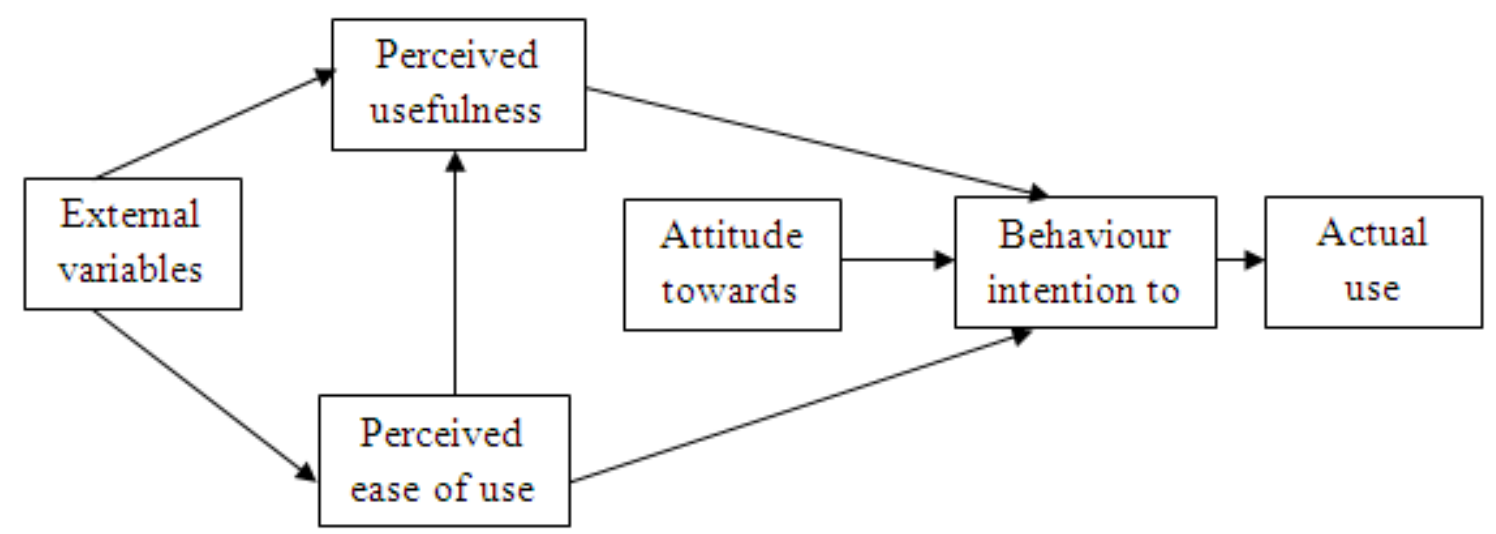

Figure 1. Original technology acceptance model (TAM) 


\section{Sample and Instruments}

The sample for the ICT-survey was ten randomly selected high schools out of two circuits in the Education Management Development Centre (EMDC) North, Western Cape in South Africa. A frequency-count questionnaire was used for the survey. For the second research question, 45 science teachers from the selected schools completed the TAM-questionnaire. Five teachers were female and $70 \%$ of the teachers were older than 30 years of age. The TAM-questionnaire consisted of items adapted from Davis[2] which were modified to be relevant to the research questions of this paper (it had a Cronbach's alpha reliability coefficient of 0.80 ). The TAM-questionnaire consists of a five-point Likert scale ranging from "strongly agree" to "strongly disagree" with a not applicable option. The items were grouped into the three categories; perceived ease of use, perceived usefulness and external control towards ICT.

\section{Data Analysis}

Data collected from the survey and questionnaire were coded and recorded in a MS-Excel program. A random sample of ten percent of the entered data was checked for coding accuracy. Multivariate analysis is usually used to analyse related variables to find correlations. This analytic technique is complex and would require extensive statistical knowledge[13]. However, for this study descriptive statistical analysis such as mean, standard deviation, frequency and percent was used to analyse and interpret the data.

\section{Results}

Figure 2 illustrates how much ICT-resource is available, in terms of percentages, at the ten selected schools and its use in the science classroom. The percentages were derived from the frequency counts of sections B and C of the ICT-survey questionnaire.

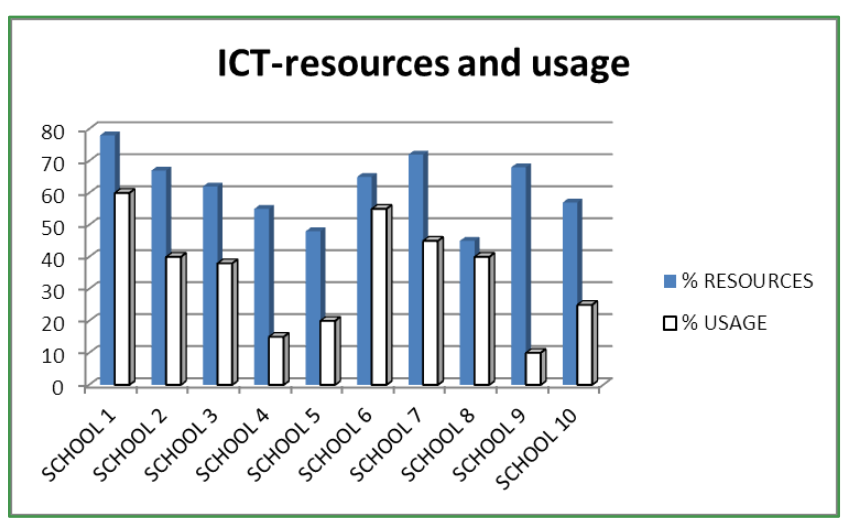

Figure 2. ICT resources and usage by the selected schools.

In examining the data in Figure 2, it indicates that all the schools have at least basic ICT-resources, because all of them are above $40 \%$. The ICT resources range from School 8 , which has the least (43\%) resources; with a data projector, a computer and internet connection in only one classroom, and School 1 the most $(75 \%)$ resources; with interactive electronic white boards, internet connection and ten computers in each science classroom.

Table 1. Frequency of factors influencing teachers' intention to use ICT

\begin{tabular}{cccc}
\hline \multirow{2}{*}{ Variables } & \multicolumn{3}{c}{ Intention to use ICT in the classroom } \\
\cline { 2 - 4 } & Frequency & Percentage & SD \\
\hline $\begin{array}{c}\text { Perceived usefulness of } \\
\text { ICT }\end{array}$ & 26 & $57.78 \%$ & 1.77 \\
\hline $\begin{array}{c}\text { Perceived ease of use } \\
\text { ICT }\end{array}$ & 15 & $33.33 \%$ & 1.25 \\
\hline $\begin{array}{c}\text { Perceived external } \\
\text { control toward ICT }\end{array}$ & 4 & $8.89 \%$ & 0.15 \\
\hline $\mathrm{N}=45$ & & & \\
\hline
\end{tabular}

Table 1 reveals that most $(57.78 \%)$ of the 45 science teachers' intention to use ICT was primarily influenced by their perceived usefulness of ICT. In this category the teachers had to respond to statements like; "ICT would improve my teaching skills.", "ICT would increase my academic productivity." and "ICT would make it easier to do my job". During the interviews the teachers generally indicated that they would complete teaching content speedily and CAL would take less effort to prepare in the long term.

The teachers who were influenced by their perceived ease of use constituted a third of the science teachers. Some of the statements of this category were, "I find the ICT-resources in my classroom easy to use.", "It is easy to become skillful at using the ICT-resources in my classroom." and "Learning how to use ICT-resources is easy for me". In the interview responses they generally commented that their capacities and abilities to use computer technology will make it easy to engage in CAL.

Perceived external control towards ICT influenced the science teachers the least $(8.89 \%)$. Some of the statements in this category were, "I have no difficulty accessing and using ICT-resources in my classroom.", "The ICT-resources in my classroom are regularly updated and is functional." and "I get the necessary technical support for the ICT-resources in my classroom". The interview comments largely revealed that most teachers experience problems in this category.

Considering the overall results, perceived usefulness appear to be the most important variable, followed by perceived ease of use and least for the perceived external control towards ICT influencing the teachers. The small standard deviation (SD) values suggest slight variability of the frequency counts in the different cohorts of teachers.

\section{Discussion}

\section{Available ICT resources at schools}

An examination of Figure 2 also shows a notable disparity between the availability of ICT resources ( $43 \%$ to $78 \%)$ in 
the schools and their frequency of use $(10 \%$ to $60 \%)$. This suggests that the resources are not being used optimally in the science classrooms. This finding is supported by the study of Mumtaz[9] who provides the following explanation for the disparity between the availability of ICT resources and their use in the schools. He asserts that:

Firstly, the culture dictates what teaching is and how learning occurs. What knowledge is proper in schools, and the learner-teacher [not learner-machine] relationship dominates popular views of proper schooling. Secondly, the age-graded school, an organisational invention of the late nineteenth century, has profoundly shaped what teachers do and do not do in classrooms, including the persistent adaptation of innovations to fit the contours of these age-graded settings.[9(p.322)]

The factors noted by Mumtaz as well as other factors mentioned by Davis[2] such as, lack of teaching experience with ICT, lack of on-site support for teachers using technology, lack of help supervising learners when using computers, lack of ICT specialist teachers to teach learners computer skills, lack of computer availability, lack of time required to successfully integrate technology into the curriculum and lack of financial support (external control) might have contributed to the low usage of ICT-resources at schools. Teachers' "phobia" for new technology could also be a contributing factor for the dispartity revealed in figure 2 .

Rosen and Well[14] also found that many teachers' technophilic propensities are because of availibility of computers and the most prominent predictor for computer use is computer experience. In addition, they also concluded that age, gender, teaching experience, computer availibilty, ethnicity and socio-economic status plays a role in some teachers' intention to make use of ICT. They further found that, younger and female teachers are more enthuistiastic to make use of ICT than their older and male colleagues. Although education authorities increase ICT availibility in classrooms, it is a challenge to make use of it, because it is not integrated effectively into the science curricula.

\section{The use of available ICT resources at schools}

Some of these factors indicated above are reflected in the responses given by science teachers that were interviewed at the selected schools. One of the questions posed to them was, "Why are the ICT-resources not used optimally at your school?"

Teacher 5 from school 2:"The content laden curriculum does not allow time for learners to work on the computers in the classroom and I will not be able to finish the work [curriculum] in time." (Perceived external control)

Teacher 9 of school 4:"Although the science learners must also use the computer laboratory of the school, it is always a fight with the CAT [computer application technology] teacher to get a turn to use it." (External control)

Teacher 6 of school 3: "I don't bother working with the computers, it is just a nuisance! The learners do not focus on the work we are doing when we are working with the computers, they fiddle around and do not pay attention to me. I am comfortable with my talk-and-chalk." (Perceived ease of use)

Teacher 13 of school 5: "I never got training to use the software on the computers; I am anyway too old for computers. I only use the interactive white board to give notes to the learners." (Perceived ease of use)

Teacher 36 of school 8: "Our PC's [computers] and software are out-dated and the licenses expired long time ago. The principal does not want to give money to update and renew the licenses of the software; therefore the computers are just white elephants in the classroom." (External control)

Whatever, one may surmise from the teachers' responses, it is difficult to ignore their genuine concerns altogether. This is because to apply ICT-resources efficaciously, they must be at ease with such resources. When a teacher is uncomfortable with a teaching tool, he/she is not likely to use it as Teacher 5 from School 2 confesses. It would be surprising if the alibis given by the other teachers were not unrelated to the same factor.

On the question whether the use of ICT-resources could improve the conception and performance of science learners, some of the teachers responded as follows:

Teacher 3 of school 1: "Learners seems to understand concepts like covalent bonding must better and quicker when they saw the simulation model of it, than when I am explaining it to them." (Perceived usefulness)

Teacher 25 of school 10:"Learners understand the workings of the computer better than I do. I am too old for computers, so sometime I just let them work on the computers in groups and let them report back to the class. You will be surprised how quickly they understand the work." (Perceived ease of use)

Teacher 18 of school 6:"I let them work through PowerPoint presentations; about work, we did in class, and let them complete worksheets at home or after school. This saves lots of time." (Perceived usefulness)

Teacher 21 of school 9:"The software programmes cover aspects that I would not normally do in class; this gives the learners a broader understanding of the work." (Perceived usefulness)

These responses suggest that ICT could help some of the teachers to address the inhibitions mentioned above. It is interesting to note that Teacher 25 from School 10 has a positive view of ICT and Teacher 13 from School 5 (response to the first question) expresses a negative, although both teachers regard themselves as too old for computers. This shows that teachers' perceptions play an important role in their attitude towards the use of ICT. Teacher 18 of School 6 has a usefulness perspective, because he allows learners to work on own pace and collaborate with each other in class. Of course, one does not know at this stage if this social instructional practice (i.e. allowing learners to work and interact together in class or after class) reflects a sort of technophobia demonstrated by Teachers 13 and 25 are a genuine professional belief of the two teachers. 


\section{Teachers' intention to use ICT}

These results supports Davis'[2] contention that, from a point of view of causality, perceived ease of use could be an antecedent to perceived usefulness rather than direct parallel determinant of usage. According to him users adopt a technology firstly on the basis of the tasks it can perform for them and then consider the level of difficulty associated with its operations. He adds that an increase in experience with the technology influences the intention of use, because in the beginning the user assesses the ease of use on the basis of self-efficacy and with time, it become instrumental. The ICT-questionnaire and TAM-interview responses support the assertion of Davis[2] that perceived usefulness influences teachers primarily in their intention to use computers in the science classroom.

In another study by Anthony, Clarke and Anderson [15] they found that teachers, who did not make use of ICT-resources in their teaching methodology, produced better results than those teachers who did make use of ICT-resources. These findings are contrary to the popular belief that use of ICT-resources will improve learners' performance. Lam[5] concurs with these findings and asserts that teachers are not really technophobic, but that institutions are perhaps overly technophilic in their rush to obtain the latest innovations without considering the needs of teachers and learners. Therefore, education authorities should not assume that all teachers will buy into and voluntarily will use the ICT-resources in the classroom.

\section{Conclusions}

This paper examined the availability and use of ICT-resources at selected schools and the teachers' intention to make use of these technologies for CAL in the science classroom. It also tries to explain why some teachers make use of or refrain from employing ICT-resources in their classrooms. The introduction of innovations in the area of information technology presented the rise of a new technological paradigm in education, which requires new practices. As Santana[16] asserts, "This new information economy asks for a new kind of worker [teacher] and a new style of management [teaching]". Therefore, it is important for the education authorities to be aware of the perceptions of teachers and teaching methodologies pertaining to ICT in the current technological era.

The results of the ICT-survey revealed that most of the schools do have sufficient ICT-resources, but it is not used optimally by teachers. This observation is confirmed by plethora of literature and supports the conclusion that some teachers have technophobic tendencies, because of their lack of computer experience, lack of ICT-integration in the curricula and their perception of the usefulness of ICT-resources. Proponents of ICT-integration into schools argue that CAL has the potential to improve learners' academic results and whole school functioning[9]. They contend that if ICT is used competently it can enhance learners' higher-order thinking skills, life-long learning habits and communication skills. On the other hand, the technophobic views held by some teachers that technology dehumanises teaching, computers are expensive, computers become quickly obsolete and that machines will take over our lives, contribute to the fact that teachers do not make use of the available ICT-resources in their classrooms. In Santana's dualistic analysis of technophobia and technophilia, she suggests that a middle range position has to be taken by education management, because new technology brings controversies and at the same time open doors for new possibilities. Therefore, the use of ICT-resources should be strongly advocated and teachers should be shown how to benefit from it, making a clear and critical analysis of what it takes to make them useful tools, and how to best use information technology to enhance the educational process. However, the technophobic tendencies of some teachers should be kept in mind.

It is therefore recommend that the education authorities and school managements should take into account teachers' perceptions on the usefulness of technology in classrooms. This could solve the problem of under-utilisation of technologies at schools. Furthermore, school management should note teachers' perceptions to make better choices when procuring ICT-resources. This because crucial in the present rapidly increasing information technology age.

Finally, these research findings are applicable to other learning areas as well. Since the result of this study was limited to only ten schools, researchers may conduct similar studies on a larger scale, especially within the South African context. Future studies could also focus on gender and socio-economic influences on the perceptions of teachers' intention to make use of ICT-resources in the classroom.

\section{REFERENCES}

[1] South Africa. Department of Education. National Strategy for Mathematics, Science and Technology Education in General and Further Education and Training. Pretoria: Department of Education; 2001.

[2] Davis FD. Perceived usefulness, perceived ease of use and user acceptance of information technology. MIS Quaterly. 1989; 13(3): 319-340.

[3] Fishbein M. Ajzen I.. Belief, attitude, intention and behaviour: an introduction to theory and research. Reading, MA: Addison-Wesley; 1975.

[4] Bertrand M. Bouchard S. Applying the Technology Acceptance Model to VR with people who are favourable to its use. Journal of CyberTherapy \& Rehabilitation. 2008; 1(2): 200-210.

[5] Lam Y.Technophilia vs. Technophobia: A preliminary look at 
why second language teachers do or do not use technology in their classrooms. The Canadian Modern Language Review. 2000; 56(3): 45-60.

[6] Geer R. Sweeney T. Students' Voices about Learning with Technology. Journal of Social Science. 2012; 8(2): 294-303.

[7] Gardner P. The Technology-Science Relationship: Some Curriculum Implications. Research in Science Education. 1990; 1(20):124-133.

[8] Kiboss J. Ogunniyi M. Outcomes of first year secondary students in Computer-augmented physics program on measurement. Learning Media and Technology. 2005; 30(3): 313-326.

[9] Mumtaz S. Factors Affecting Teachers' use of Information and Communications Technology: A Review of the Literature. Technology, Pedagogy and Education. 2000; 9(3): 319-342.

[10] Layton D. Technology's Challenges to Science Education. Philadelphia: Open University Press; 1993.
[11] Venkatesh V. Morris M. Davis G. Davis F. User accetance of information technology: toward a unified view. MIS Quaterly. 2003; 27(3): 425-478

[12] Davis FB. Warshaw P. User acceptance of computer technology: A comparison of two theoretical models. Management Science. 1989; 35(8): 982-1003.

[13] Ogunniyi M. Educational Measurement and Evaluation. Ngeria: Longman; 1984.

[14] Rosen LD. Well MM. Computer availibility, computer experiences and technophobia among public schools teachers. Computers in Human Behaviour. 1995; 11(1): 9-31.

[15] Anthony LM. Clarke MC. Anderson SJ. Technophobia and personality subtypes in a sample of South African university students. Computers in Human Behaviour. 2000; 16(1): $31-44$.

[16] Satana B. Introducing the Technophobia/Technopilia debate; Some commments on the information age. Education, Technology \& Society. 2003; 10(2):1-8 